\title{
Social Media: A Security Threat amongst Adolescents in Buea, Cameroon?
}

\author{
Kingsley L. Ngange ${ }^{1}$, Vera T. Fonkem ${ }^{2}$, Stephen N. Ndode ${ }^{3}$ \\ ${ }^{1}$ Chair, Department of Journalism and Mass Communication, University of Buea-Cameroon \\ ${ }^{2} \mathrm{Ph}$.D Student, Department of Sociology and Anthropology, University of Buea-Cameroon \\ ${ }^{3}$ Instructor / Ph.D Candidate, Department of Journalism and Mass Communication, University of Buea-Cameroon \\ Correspondence: Kingsley L. Ngange, Chair, Department of Journalism and Mass Communication, University of \\ Buea-Cameroon. E-mail: kngange@yahoo.com
}

Received: September 25, 2019

Accepted: November 9, 2019

Online Published: November 11, 2019

doi:10.11114/smc.v7i2.4613

URL: https://doi.org/10.11114/smc.v7i2.4613

\begin{abstract}
Social media provide a platform through which societies can either be constructed or destabilized. In view of the ongoing bloody conflicts in Cameroon, this study examines the extent to which social media could pose as a security threat (with particular focus on community security) amongst adolescents in Buea, capital of the South West Region in Cameroon. The study uses a quantitative approach, through the collection of data from adolescents in four communities in Buea (Muea, Bomaka, Mile 16, and Molyko). These four areas are selected because the current socio-political crisis rocking the two Anglophone regions of the country - Northwest and Southwest, is particularly severe in these communities. Social media (notably Facebook and WhatsApp) spread dangerous content, and adolescents are vulnerable to such content. Findings indicate that there is a high rate of social media use (Facebook and WhatsApp) amongst adolescents surveyed. Also, the most discussed items on social media are socio-cultural issues (68\%), as opposed to political issues (17.8\%). Respondents were receptive to discussions on socio-cultural issues like dressing, language and relationships. Results also show that though adolescents come across violent content on social media, they have distanced themselves from being involved in the production, consumption, and dissemination (for instance, share information as received) of such violent content, partly because of the judicial consequences of doing so, as contained in the country's Terrorism Law of December 2014. The implication here is that, since the adolescents are not yet intoxicated (whether advertently or inadvertently) with destructive social media content, need exists for the effective education of the adolescents, to enable this vulnerable and younger population to continue desisting from negative social media content. Emphasis should be on the consumption of positive social media content that helps in the moral and psychological growth of adolescents.
\end{abstract}

Keywords: social media, security threat, community security, adolescents, Buea-Cameroon

\section{Introduction}

First we build tools and they build us.... We become what we behold.... We shape our tools...... Our tools in turn shape us (McLuhan, 1964, p.21).

This assertion highlights the symbiotic relationship between media technologies and humans. In contemporary times, it is difficult to imagine a separation of the study of these two concepts. The United States National Security Strategy acknowledges that the very technologies that empower humans to lead and create, also empower those who would disrupt and destroy (United States National Security Strategy, 2010). Similarly, changes in technology transform the social construct, which in turn shape perceptions, experiences, attitudes and behaviour (MacKenzie \& Wajcman, 1999).

Following the development of mass media (radio in the 1920s, television in the 1940s, and Internet in the 1960s), conflicts have remarkably increased around the world (Manoff, 1998; Zeitzoff, 2011).

A framework for understanding social media's influence during conflict can be seen in the following domains: it increases the speed and dissemination of information and it transforms the information available to conflict actors, thereby shaping the conflict itself (Zeitzoff, 2017). This aligns with the view that social media helps to mobilize, manipulate and expose violence and injustices in the society (Joachim, 2017). Social media can therefore be seen as having both positive and negative influences during conflict situations.

Developments in the Arab world in what has come to be known as the Arab awakening or Arab Spring, have reinforced 
the role the media continue to play in shaping human behaviour and perceptions. This has a spiral effect in what is happening in democracies across the world today, including Cameroon; the radical demand for change via the social media in particular and the mass media in general. The Anglophone crisis in Cameroon started in October 2016 with lawyers and teachers asking for professional reforms. Unfortunately, the crisis has spiralled into an armed conflict, in which separatist fighters are calling for the secession of the English part $\left(1 / 5^{\text {th }}\right)$, from the French part $\left(4 / 5^{\text {th }}\right)$ and creation of an imaginary Ambazonia State. The English part of Cameroon reunited with the French part in a plebiscite in 1961, after over 40 years of colonial rule by the British and French. The major reason for their call to secede is marginalisation. So far, the crisis has left over 3000 people dead, about 200,000 internally displaced and over 100,000 as refuges in Nigeria.

During the early days of the crisis, separatists created Facebook pages / groups like Ambazonian Freedom Fighters, and widely spread messages on WhatsApp, to rally the masses, especially those from English speaking Cameroon as well as Anglophones in the Diaspora against the government. Through these pages, activists gained momentum to initiate strike actions and imposed ghost towns. Thus, confirming that Facebook and WhatsApp posed security threats by intensifying conflicts in their role as media. Activists use them to build their coercive apparatus (Gohdes, 2015).

The spread of social media, driven by Internet boom and mobile technology, is fast changing the way society operates (Ungerer, 2012). Communication has for long been seen as an important means in the setting of human socialization (Lustig \& Koester, 1999).

The use of these media platforms is likely to cause several negative effects for national security and unfavourable consequences for a state's strategic interests. Nevertheless, their use can also lead to remarkable opportunities for a country, in order to reach its strategic relevant goals, understand how threats will work in the future, and figure out how to counter their effects (Montagnese, 2011). Also, social media, a subset of ICTs, can be understood as online tools and utilities that allow for the dissemination of information online as well as participation and collaboration (Newson, Houghton \& Patten, 2018). Similarly, social media can be viewed as online communications which use special techniques involving participation, conversation, sharing, collaboration and linkages (Chadwish, 2006).

According to the Hague Centre for Strategic Studies (2011), the level of penetration of social media into everyday life is soaring and is expected to see a marked increase not only in the near future, but also in the long run.

Technology has many positive aspects, but when poorly used, it can become dangerous. For adolescents, the online realm may be adopted enthusiastically because it represents their space, visible to the peer group more than to adult surveillance (Drotner \& Livingstone, 2008). The term Adolescence was introduced in the early $20^{\text {th }}$ Century, and described as a distinct period between childhood and adulthood (Hall, 1904). It is a complex period of growth and change in a variety of domains and certainly the lead age group all over the world with the most paid attention (Dacey \& Kenny, 1994). This period of adolescence lasts for about a decade, extending from 11years to early 19 (Hayford \& Furstenberg, 2008).

The magic bullet theory bases on the assumption that, people are considered to be uniformly controlled by their biologically based instincts and that, they react more or less uniformly to whatever stimuli comes along. It assumes that the media's message is a bullet fired from the media gun into the viewer's head (Lowery \& DeFleur, 1995). Similarly, it suggests that the media injects its messages straight into the passive audience. This passive audience is immediately affected by these messages. In such circumstances, the public, especially young people, are vulnerable to the messages shot at them. The viral nature of social media makes this case stronger.

It may not be an exaggeration to assert that many modern day young people make use of social networks on a daily basis (Boyd \& Ellison, 2008). Thus, they cannot escape from media influence (Berger, 1995). 22\% of young people log on to their favourite social media sites more than 10 times a day (Common Sense Media, 2009).

Prominently discussed concerns will all revolve around personal risks such as exposure to and contact with inappropriate content and people; for instance, pornography, violence, hate filled material, sexual predators, cyber bullies, as well as violent and criminal acts. All these put together, might pose security threats on the individual and the society as a whole. Drussell (2012) and Ringrose (2006, 2008) have also emphasized that need exists to pay attention to cyber bullying because of the detrimental effects on victims, including feelings of depression, guilt, and shame, which can lead to self-harm and withdrawal from family and friends. The same negative consequences can befall adolescents if they engage in wrong use of social media.

Security here is increasingly viewed as an all-encompassing condition in which people and communities live in freedom, peace and safety (UNDP, 1994). The people participate fully in the governance of their countries, enjoy the protection of fundamental rights, have access to resources and basic necessities of life, and inhabit an environment which is not detrimental to their health and wellbeing. 
In the past, researchers and government officials frequently put threats to national security as top priority among all security issues. For example, military conflicts. Thus, an issue or event would only be classified a security threat if the survival of the state as an entity was at risk (Lippmann, 1943). However, following the new paradigm shift, several types of human security have been distinguished to include environmental, personal, physical, economic, social, political, and cultural security. The main area of focus for this research is community security. Community here does not only refer to individual community members, but to all actors, groups and institutions within a specific geographic space (Jolly \& Ray, 2006). Furthermore, community security is considered as protecting people from the loss of traditional relationships and values, and from sectarian and ethnic violence (UNDP, 1994).

This paper is based on a theoretical approach that considers young people as active agents who can manipulate, adapt, create, and disseminate ideas and products through communication technologies. The case of Buea, a town located at the foot of Mount Fako in the Southwest region of Cameroon, is no exception to social media use, and the consequent effects that may follow, classified as security threats amongst adolescents.

What then is the problematic of this research? The potentials for ICTs to bring about meaningful changes in the society cannot be disputed. Cameroon, like any other country in the world is not immune to forces of social media use and misuse. The use of social media as a new communication platform introduces security and privacy concerns, including new vectors for cyber-attack that the government and the military cannot ignore. Criminal gangs, terrorist organizations and non-state individuals use social media to send alarming messages, hate speeches and false information to the public regarding the state of national security affairs. Some of the social media users remain anonymous and cannot be easily traced by law enforcement agencies for subsequent prosecution. States therefore are faced with tough challenges to track, monitor and contain the use and misuse of social media.

The central issue therefore builds around the argument that though technology has both positive and negative effects, if left uncensored, the negative effects could assume far-reaching consequences on adolescents. Likely deviant behaviours amongst adolescents may plunge the country into an ungovernable state, deep crises, and chaos.

The main objective of this paper is to examine how the use of social media platforms (Facebook and WhatsApp) within the Buea municipality affects the lives of adolescents and the likelihood of exposing them to different dimensions of security threats. Specifically, the study seeks to:

- Identify the use patterns of Facebook and WhatsApp amongst adolescents;

- Examine the various dimensions of security threats resulting from the use of social media; and

- Assess possible ways by which social media's influence on adolescents can be mitigated.

Three research questions are used:

RQ1: How do adolescents in Buea, Cameroon, use Facebook and WhatsApp?

RQ2: What are the various dimensions of security threats that result from the use of social media platforms by adolescents in Buea, Cameroon?

RQ3: What possible measures can be put in place to counter the ill effects of social networking on adolescents?

This study is limited to the appreciation of contents adolescents come across on social media platforms and how such contents affect them, leading to different dimensions of security threats. In as much as the study recognises that new interactive technologies impact other age groups outside the adolescent bracket, the study limits itself to adolescents only. It focuses on four communities: Mile 16, Muea, Molyko and Bomaka in the South West Region of Cameroon, where adolescents are particularly vulnerable to poor social media content.

\section{Social Media Dynamics and Adolescent Behaviour}

O'Reilly (2005) remarks that social media cannot be discussed in broad terms without first of all understanding Web 2.0. This is because social media were developed based on Web 2.0 technologies. To him, collective intelligence is one of Web 2.0's fundamental features. In this context, Web 2.0 is of the user, by the user, and, for the user.

In a text entitled Social media Bible, Safko, Lon, and Brake (2009) brought to limelight a nearly limitless amount of possibilities on the Internet. They classified examples of Web 2.0 Social media to include blogs, which refer to individuals or groups producing ongoing narratives of information; wiki, which includes collaborative information production and collection; Facebook and Myspace which are streamlined social networking programs; Flicker, which is a highly accessible photo sharing software; YouTube, a community-based video sharing software; Google Maps which include mapping software enabling collaborative point of interest sharing; Amazon user reviews, a comprehensive user contribution to product reviews; Twitter with its wide followership patterns; and the Facebook and WhatsApp technology which have become widely used across all age groups. 
In a similar manner, Kaplan and Haenlein (2010) propose six different types or categories of social media which include collaborative projects, blogs and micro-blogs, content communities, social networking sites, virtual game worlds and virtual communities. This articles asserts that these platforms and contents are capable of shaping the way adolescents perceive and interact with the world around them.

To Leavey (2013), social media are social structures made of modes comprised of individuals or organisations, tied by one or more specific types of interdependencies such as values, ideas, financial exchange, friendship, kinship, dislike, conflict or trade. He believes that this innovative tool brings together people of common value systems, visions and aspirations to collaboratively form opinions on issues of concerns in virtually connected environments.

Social media is part of a wider trend in communication landscape that is characterised by mass collaboration; it is responsible for a significant portion of time spent online (Pinzon, 2013; Dobson, 2014a; Dobson, 2014b). In the context of this study therefore, social media refers to online tools that permit real-time interactions and feedback. Consequently, four productions of social media are evident: text, audio, video, and images. The context within which adolescents use any of these forms is likely to be motivated by the individuals they are communicating with, and the environment.

Mbayong (2017) in an article entitled, 'Assessing the impact in the growth of Social Media in Cameroon and User Experience: The Case of Facebook', reveals that Facebook is more appealing to females and teenagers. When used appropriately therefore, Facebook is likely to contribute in enhancing the reproduction of dominant culture and hegemony and the presence of a feminine discourse of empowerment (Garcia-Gomez, 2014, 2017, 2018).

Friedrich-Ebert Stiftung, in a work titled 'Social media for social participation and political change in Cameroon' emphasises that, social media in Cameroon is mostly used by young people who express themselves on matters of public concern. They use social media to make their voices heard as they are victims of exclusion. In Friedrich Stiftung's perspective, social media is poorly developed because of limited Internet access and poor connectivity.

\section{Social Media, Adolescents, and Security Concerns}

The United States Youth Internet Safety Survey (2018) conducted by Crimes against Children Research Centre at the University of New Hampshire interviewed 1,501 youth aged 10 to 17 years that frequently used the Internet. It was found that $77 \%$ of youth have received an unwanted sexual solicitation through the web, yet, only $24 \%$ of teens told a parent about the solicitation. $19 \%$ told a peer and $31 \%$ of teens were not worried by the sexual online solicitation. At this point, Internet content can become counter-productive for children if not well managed.

In their work entitled 'Teens, Social Media, and Privacy' Madden et al (2013) report that teens' Facebook friends are a reflection of their offline social network of friends. In other words, they know most of their Facebook friends personally. They include friends from their school and other schools, and friends of members of their extended family, parents, and siblings. Other Facebook friends are teachers, coaches, and celebrities such as musicians and athletes. This view is corroborated by Garcia-Gomez (2007 and 2011), whose discourse includes language, construction of gender identities, and sexuality.

Research on adolescents carried out by Livingstone and Bobber (2005) reveals that $57 \%$ of 9 to 19 years old have come into contact with online pornography. Their encounters with pornography happened in different ways. The most common was in pop-up adverts, or open porn sites accidentally when looking for something else or in junk mail. The authors further emphasize that at the heart of the explosion in online communication is the desire to construct valued representation of oneself which affirms and is affirmed by one's peers. The survey data indicates that $48 \%$ of youth said they use the Internet to improve their relationships with friends, and 32\% said they use the Internet to make new friends.

Garcia-Gomez (2017), O'Keeffe and Clarke-Pearson (2005), and Ringrose (2010) also highlight the consequences of some identified risks of youth social media use such as sexting and privacy issues. Sexting is using digital devices such as computers and cell phones to send, receive, or forward sexually explicit photographs, images, or messages. These images can then be shared and distributed rapidly. The consequences of sexting include emotional stress and accompanying mental health conditions for perpetrators, school suspensions, and in some cases, child pornography charges. Activities that put young people's privacy at risk include sharing vital personal information and posting false information about themselves or others. The authors emphasize that teens can be ignorant of their digital footprint - the record of their web activities - and the fact that whatever they post online becomes a permanent record. There are many problems and risks associated with youth social media use. One of the major risks is cyber bullying (Ringrose, 2008); the act of posting hurtful, false, and embarrassing information about another person.

Meanwhile, Bryant, Sandals-Jackson and Smallwatt (2006) and Garcia-Gomez (2009) indicate that young people use socially interactive technologies to enhance communication among friends and family, to make plans with one another, and to maintain social contact outside of their day to day and face-to-face conversations. That is why Valkenburg, Peter, and Walther (2016) found that Internet communication positively relates to the time spent with friends and the quality of 
existing adolescent friendships. Ringrose, Gill, Livingstone, and Harvey (2013) opine that these characteristics may encourage intimate self-disclosure as a predictor of reciprocal liking, caring, and trust.

In a study about the role of the Internet and social media in international relations with particular focus on the Arab revolution, Cunman (2011) focused on the extent to which social networks such as the Facebook, Twitter, YouTube and weblogs played instrumental roles in facilitating uprisings in Egypt, Tunisia and Syria. The study found that the usage and growth of social media in the Arab region played a great role in mass mobilization of protestors, empowerment, shaping of opinions and influencing change. To date, such Arab countries have witnessed constant conflicts and political instability, coupled with widespread social unrest negatively affecting broader sets of economic, social, and political factors. Social media therefore becomes a tool rather than the actual cause of the revolution.

Njoroge (2013) sought to investigate the impact of social media among youths on behaviour change, with case study being university students in selected universities in Nairobi, Kenya. The study found that youths in Kenya highly use social media, and they spend more time on the computer. The study further suggests that the youths mostly use Facebook, Whatsapp and Twitter. Care should be placed on the efficient and positive use of these technologies, as they are likely to influence the behaviour of youths (Ringrose, 2011; Ringrose \& Renold, 2012). Content accessed on social media forms an important process of socialization for 21st century adolescents (Garcia-Gomez, 2007).

On his part, Kassam (2013) discusses the role of digital social media in teaching Kenyan students responsible citizenship in a democracy. He mentions that skills such as having respect for all, irrespective of race, ethnicity, socioeconomic status, taking a moral stance on issues, showing concern for others, and possessing the ability to argue respectfully with others, can be taught in the classroom. However, he argued that in the broader context of knowledge acquisition and communication within and outside the country, it is important to include digitized media technologies in the curriculum to impart critical media literacy skills to students. Such skills can help prevent mass violence, protests, and demonstrations, which can be caused by students disregarding their civic responsibilities and not respecting the rights of others.

A study by Buhari, Ahmad, and Bashir (2014) reveals that students prefer to use Facebook and WhatsApp to share information; communicate with friends; access movies, photos, and music; search for jobs; propagate their religion; and conduct business. The Nigerian study equally revealed that a majority of students use social media more than five hours per day.

From this literature assessment, the stance of the authors of this article is that social media (Facebook and WhatsApp particularly) can be beneficial to adolescents if these media are positively used for informative and educative purposes. On the contrary, adolescents will be affected negatively (psychologically or emotionally) if social media content become counter-productive to their wellbeing. Suggestions point to the direction of having adolescents use Facebook and WhatsApp in a typically engaging, proactive, and resourceful manner.

\section{Theoretical perspective}

This study is premised upon two theoretical perspectives: Technological Determinism Theory and the Social learning theory.

Technological Determinism states that media technology shapes how individuals in a society think, feel, act, and how the society operates as it moves from one technological age to another. This theory was developed by Marshall McLuhan. It explains that individuals learn, feel, and think the way they do because of the messages they receive through the current technology that is available. The medium is then the message. Social media brought about by emerging technology requires people to be engaged often. People then interpret the messages sent to them from social media in their everyday life. With respect to this theory, humans do not have much free will at all. Whatever society as a whole is using to communicate, they too will use to communicate. Therefore, they will adapt to the medium they are using so that they can send and receive messages like everyone else. As the medium changes, so does society's way of communicating. People can only use the medium for which it was created (phone for talking over lines or electronic mail for communicating via computer). If the medium is impersonal (mobile phone), then the message too is impersonal.

This theory assumes that when new systems of technology are developed, the culture or society is immediately changed to reflect the senses needed to use the new technology. Winner (1977) supports McLuhan's idea by asserting that the core assumption of technological determinism is that technology forms the basis of social life and that "changes in technology are the single most important basis of change in society" (p.65). The theory predicts that with every new system of media technology, society will change and adapt to that technology. Therefore, there is a cause and effect analysis between the introduction of new technology and the changes in society's way of thinking, feeling, acting, or believing. This is closely related to what the researchers seek to understand, that is, how access to social media may 
likely influence the way young people in the Buea municipality think, act or feel. This could be reflected in their ethics, mannerisms, dressing styles, and overall communication patterns.

Despite its criticisms, the technological determinism theory is relevant to this study because, according to McLuhan's original conceptualization, changes in communication technology inevitably produce profound changes in both culture and social order. These changes are even more evident today, considering that technology is having continuous influence on individuals, cultures, and society. This study has, for instance, demonstrated that adolescents actively engage in the use of social media platforms. It is therefore, evident that the contents they interact with on such platforms have a tendency to shape and model their being, including modes of social interaction.

Secondly, according to Bandura's social learning theory, learning occurs through observations and interactions with other people. Essentially, people learn by watching others and then imitating these actions. The experiment involved exposing children to two different adult models; an aggressive model and a non-aggressive one.

Bandura goes further to make several predictions about what the possible outcome might be. He forecasts that children who observed an adult acting aggressively would be likely to act aggressively even when the adult model was not present. Bandura emphasizes that the children who observed the non-aggressive adult model would be less aggressive than the children who observed the aggressive model, and the non-aggressive exposure group would also be less aggressive than the control group. He also predicts that children would be more likely to imitate models of the same sex rather than models of the opposite sex. In his perception, boys would behave more aggressively than girls.

In this broad model, each child was tested individually to ensure that behaviour would not be influenced by other children. The child was first brought into a playroom where there were a number of different activities to explore.

In the non-aggressive condition, the adult model simply played with the toy and ignored the Bobo doll for the entire period. In the aggressive model condition, however, the adult models would violently attack the Bobo doll. This sequence of physically aggressive acts was repeated three times, interspersed with verbally aggressive responses.

The results of the experiment supported some of the original predictions.

- Children exposed to the violent model tended to imitate the exact behaviour they had observed when the adult was no longer present.

- Children in the non-aggressive group would behave less aggressively than those in the control group. The results indicated that while children of both genders in the non-aggressive group did exhibit less aggression than the control group, boys who had observed an opposite-sex model behave non-aggressively were more likely than those in the control group to engage in violence. Critics further castigated this view with the argument that, acting violently towards a doll is a lot different than displaying aggression or violence against another human being in a real world setting.

There were important gender differences when it came to whether a same-sex or opposite-sex model was observed. Boys who observed adult males behaving violently were more influenced than those who had observed female models behaving aggressively. Interestingly, the experimenters found that in the same-sex aggressive groups, boys were more likely to imitate physical acts of violence while girls were more likely to imitate verbal aggression.

The relevance of the social learning theory to this research is that adolescents learn through observation and interaction. Adolescents can be influenced by social media, and thus, learn new attitudes, behaviours, and habits. Since adolescence involves emotions and actions, this research is curious about the influence of the social media on adolescents' emotions vis-à-vis security threats.

Both theories are relevant in this research considering that social media is a force to reckon with in the lives of young people today. Through observation of online and offline behaviour, their patterns of behaviour in society are shaped.

\section{Methodology}

This study uses the quantitative approach. Quantitative data were collected from 90 adolescents in four localities in Cameroon, in order to determine the relationship between adolescents' use of social media viz-à-viz security threats. The study specifically uses a descriptive survey to gather data relating to security issues that arise as a result of social media use amongst adolescents in the Buea municipality. This will be in relation to violent language, violent behaviours, dress patterns and other ethical issues. The nature of this research necessitates that, the participants' knowledge, views, understanding, interpretations, experiences and interactions are considered in order to construct standard knowledge on the impact of social media on adolescent behaviour, perceptions, and attitudes.

Buea Sub division stretches between Latitude $4^{0}$ and $4^{0} 20$ north of the equator and Longitude $9^{0}$ and $9^{0} 20$ east of the Greenwich meridian (Buea Council, 2016). It is bounded to the West by Mount Cameroon with height of $4095 \mathrm{~m}$ above sea level, to the East by Tiko Sub division, to the North by Muyuka Sub division and to the South by Limbe. Buea has a 
surface area of $870 \mathrm{~km}^{2}$ Buea is the capital of the South West Region of Cameroon and has evolved from the historic capital of German 'Kamerun' to an administrative and educational headquarter, as well as a touristic hub in Cameroon. The city comprises of several communities and is politically, economically and socially active. Buea also served as Capital of British Southern Cameroons. As a result, the current Cameroon Anglophone Crisis, in which Separatists are advocating for the separation of the English part from the rest of the country, has once more brought to prominence the historic city of Buea. The separatists have described Buea as their final destination, which if "conquered" in the ongoing skirmishes between the government security forces and separatist fighters, will symbolise their secession and creation of their imaginary Ambazonia State.

The target population for this study includes adolescents from four specific communities of the Buea municipality, which include Muea, Mile 16, Bomaka, and Molyko. These communities have been chosen following security reports which identified them as zones with persistent security challenges in the ongoing crisis. The researchers sampled young people on security issues in relation to social media. The sample is distributed as follows:

Table 1. Sample distribution of adolescents who participated in the study

\begin{tabular}{lc}
\hline Community & Sample \\
\hline Muea & 25 \\
Mile 16 & 22 \\
Bomaka & 22 \\
Molyko & 21 \\
Total & $\mathbf{9 0}$
\end{tabular}

The quota or proportionate sampling technique was used. This technique is often used in survey research when it is not possible to list all the members of the population of interest (Amin, 2005). Also, the reason for this technique is because the exact number of adolescents in the Buea municipality is not known. When contacted, the statistics office could not provide this information. The period (height of insecurity) when the study was conducted also justifies the sample available for the research. The communities were deserted because of the conflict. So, fewer adolescents were available for the study.

The questionnaire for the study was structured into the following sections: frequency of social media use by adolescents, social media use during the Anglophone crisis, dimensions of security threats posed, proposed measures to counter the ill effects of social media, and demographic characteristics. The data were analysed with use of the Statistical Package for Social Sciences (SPSS).

The Cronbach's Alpha was used to measure the reliability and internal consistency of the items used in the questionnaire to examine social media (Facebook and WhatsApp) as a community security threat on adolescents in Buea (Muea, Mile 16, Molyko, and Bomaka). This measure is used because it adequately tests how closely related the set of items in the questionnaire are as a group, as well as the rigour with which the instrument was constructed. The reliability statistics is presented in the table below:

Table 2. Reliability Statistics

\section{Cronbach's Alpha}

.825
Number of Items

69

The value of the Cronbach's Alpha (.825) suggests that there is a high level of internal consistency for items measured in this study. Cronbach (1951) suggested that for any given measure of internal consistency to be deemed appropriate, the statistics must display a figure of at least $\mathbf{. 7 0}$. The statistics of internal consistency in the current study however exceed this figure, thereby further strengthening the point that these items selected to measure the major concepts and constructs of the study were well defined. It also shows that the instrument is simplistic, thereby permitting logical and correlated responses to the questions. In addition, the statistics of internal consistency also attest that respondents understood the elements in the questionnaire and thus, have given the best of their understanding of the questions at each level.

\section{Demographic Characteristics of Sample}

A total of 90 respondents took part in this research. Of this number, $53(58.9 \%)$ are male while $37(41.1 \%)$ are female. There is no particular importance attached to this gender disparity, and it does not in any way affect the results of the study. Rather, emphasis is to assure that to some extent, males and females are represented in the study. By so doing, since the research is not gender sensitive (neither for females alone nor for males alone), it is apt to study the overall 
representation of what both sexes have inputted in terms of their knowledge and use of Facebook and WhatsApp as a community security threat. This gender factor places the analysis within the broader context of the study, considering that both males and female adolescents in Buea are exposed to Facebook and WhatsApp on a routine basis. The researchers observed that more males were willing to participate in the research than females.

The age range of the respondents suggests that majority of them $(86,95.6 \%)$ are aged between 15 and 18 years, while only $4(4.4 \%)$ are aged between 11 and 14 years. The respondents are of the younger generation, and the research is meant to specifically target them. This is so because they are a vulnerable population. With recent advancements in technology, mobile phone ownership and use is rampant, even amongst these adolescents. With the increasing mix of the type of contents circulated on social media, it is paramount therefore to understand how these adolescents use the social media, and the likely effects Facebook and WhatsApp are to have on their perception of violence around their environments.

The level of education of respondents shows that most of them are Advanced level holders (44, 48.9\%), 30 (33.3\%) are Ordinary level holders, and 16 (17.8) are First School Leaving Certificate holders. This trend was expected, given that the maximum age for the research is 18years. Thus, these respondents constitute the knowledge base for responses gathered in this study. The level of education is also important here, given that it is likely to correlate with respondents' experiences in using Facebook and WhatsApp, as well as behaviours and interactions with the different messages they come across on social media (Facebook and WhatsApp).

As regards the favourite language of daily communication, evidence suggests that the dominant language is English, that is, 82 respondents (91.1\%). This is not surprising, given that the area of study (Buea) is mostly Anglo-Saxon. Only 8 respondents $(8.9 \%)$ of respondents use French as the dominant language of daily communication. Traces of French respondents in this study, though a minimal proportion, shows some traces of cultural diversity, embodied in the bilingual (English and French) nature of the country.

Research question 1: How do adolescents in Buea, Cameroon, use Facebook and WhatsApp?

\section{Facebook Use}

Respondents were asked to identify the frequency with which they use Facebook, including preferred time of Facebook use, and the persons they usually communicate with. Also, respondents were questioned on the year they started using Facebook, with evidence suggesting that majority (22.2\%) started using Facebook in 2015. Meanwhile, 2014, 2017, and 2018 each has 12 respondents (13.3\%) showing their start of use of Facebook. Only 16 respondents (17.8\%) used Facebook between 2009 and 2013, while 7 respondents (7.8\%) did not indicate the year they started using Facebook.

In addition, respondents categorized the different means they use to access Facebook as follows:

Table 3. Frequency of use of Facebook

\begin{tabular}{lcccccc}
\hline & \multicolumn{7}{c}{ Extent } \\
\cline { 2 - 7 } Device & Always & Often & Sometimes & Rarely & Never & Total \\
Mobile Phone & $\mathbf{4 9}$ & $\mathbf{1 5}$ & 14 & 11 & 1 & 90 \\
& $\mathbf{( 5 4 . 4 \% )}$ & $\mathbf{( 1 6 . 9 \% )}$ & $(15.5 \%)$ & $(12.2 \%)$ & $(1.1 \%)$ & $(100 \%)$ \\
Cyber Café & 7 & 1 & 10 & 19 & 33 & 90 \\
& $(7.8 \%)$ & $(1.1 \%)$ & $(11.1 \%)$ & $(21.1 \%)$ & $(58.9 \%)$ & $(90 \%)$ \\
Laptop & 13 & 9 & 8 & 16 & 44 & 90 \\
& $(14.4 \%)$ & $(10 \%)$ & $(8.9 \%)$ & $(17.8 \%)$ & $(48.9 \%)$ & $(100 \%)$ \\
\hline
\end{tabular}

Source: Fieldwork, 2018

Table 3 shows that most respondents access Facebook on their mobile phones (mean $=4.1)$, while cyber cafés $($ mean $=$ 1.7 ) and access using the laptop (mean $=2.2$ ) have relatively low ratings. The above statistics conform the power of the mobile phone in the $21^{\text {st }}$ Century, especially as everyone, and even adolescents want to identify with the device through ownership and use.

Again, respondents rated the time of the day they prefer accessing Facebook as seen in Figure 1 below: 


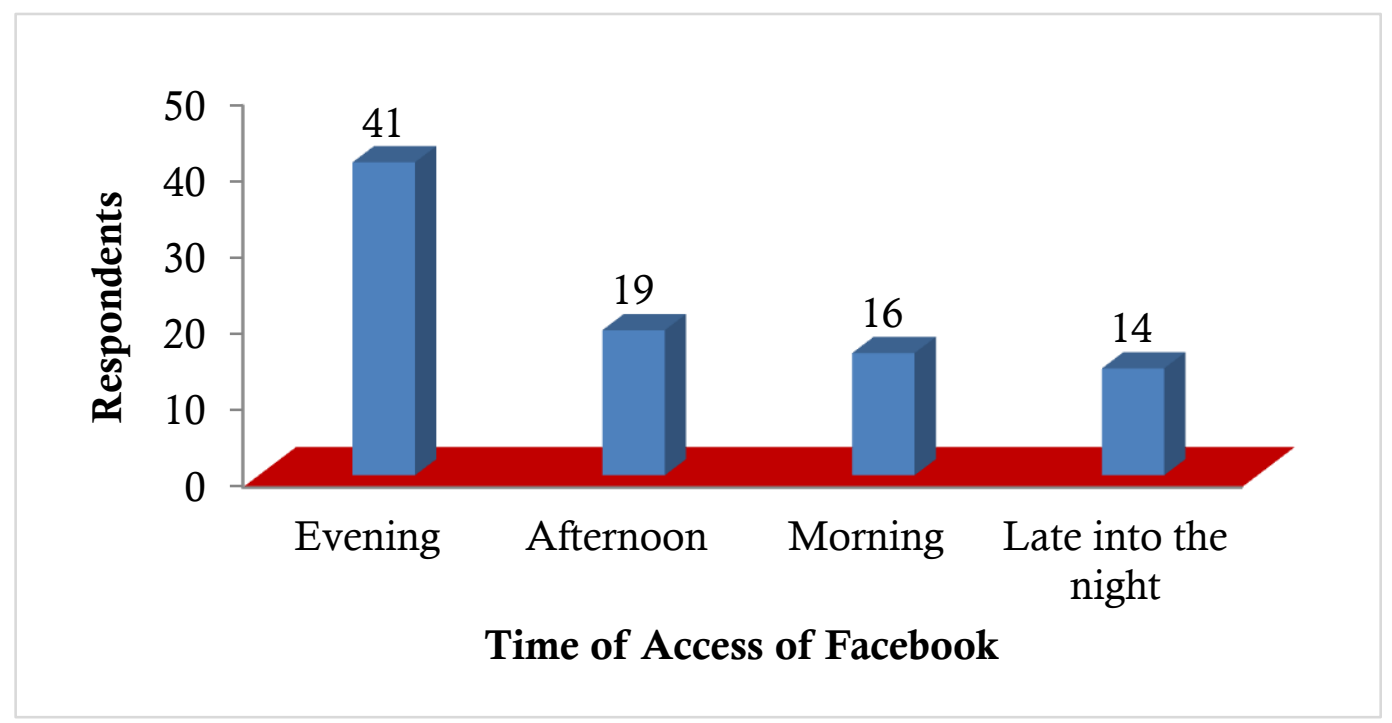

Figure 1. Time of the day respondents prefer accessing Facebook

Source: Fieldwork, 2018

As shown in Figure 1, majority of respondents prefer accessing Facebook in the evening. This is followed by access in the afternoon, morning, and late into the night. It can thus be summed that majority of respondents' interactions with Facebook content takes place in the evening.

Respondents were also asked to indicate the frequency with which they communicate with different persons on Facebook. This is shown in Table 4:

Table 4. Target group of Facebook users

\begin{tabular}{lcccccc}
\hline \multirow{2}{*}{ Persons } & \multicolumn{7}{c}{ Extent } \\
\cline { 2 - 7 } Male friends & Always & Often & Sometimes & Rarely & Never & Total \\
& 41 & 10 & 24 & 13 & 2 & 90 \\
Female friends & $(46.6 \%)$ & $(11.1 \%)$ & $(26.7 \%)$ & $(14.4 \%)$ & $(2.2 \%)$ & $(100 \%)$ \\
& $\mathbf{4 6}$ & $\mathbf{1 3}$ & 17 & 13 & 1 & 90 \\
My parents & $(\mathbf{5 1 . 1 \% )}$ & $(\mathbf{1 4 . 4 \% )}$ & $(18.9 \%)$ & $(14.4 \%)$ & $(1.1 \%)$ & $(90 \%)$ \\
& 14 & 7 & 11 & 23 & 35 & 90 \\
Relatives & $(15.6 \%)$ & $(7.8 \%)$ & $(12.2 \%)$ & $(25.6 \%)$ & $(38.9 \%)$ & $(100 \%)$ \\
& 19 & 8 & 19 & 29 & 15 & 90 \\
& $(21.1 \%)$ & $(8.9 \%)$ & $(21.1 \%)$ & $(32.2 \%)$ & $(16.7 \%)$ & $(100 \%)$ \\
\hline
\end{tabular}

Source: Fieldwork, 2018

From Table 4 above, it can be seen that respondents communicate most with their male friends on Facebook $($ mean $=$ $4.0)$, followed by communication with male friends (mean $=3.8)$, relatives (mean $=2.8)$, and parents $($ mean $=2.3)-$ below average. This clearly shows that the least category of persons respondents interact with on Facebook is their parents.

The number of hours respondents spend on Facebook daily is shown as follows: 


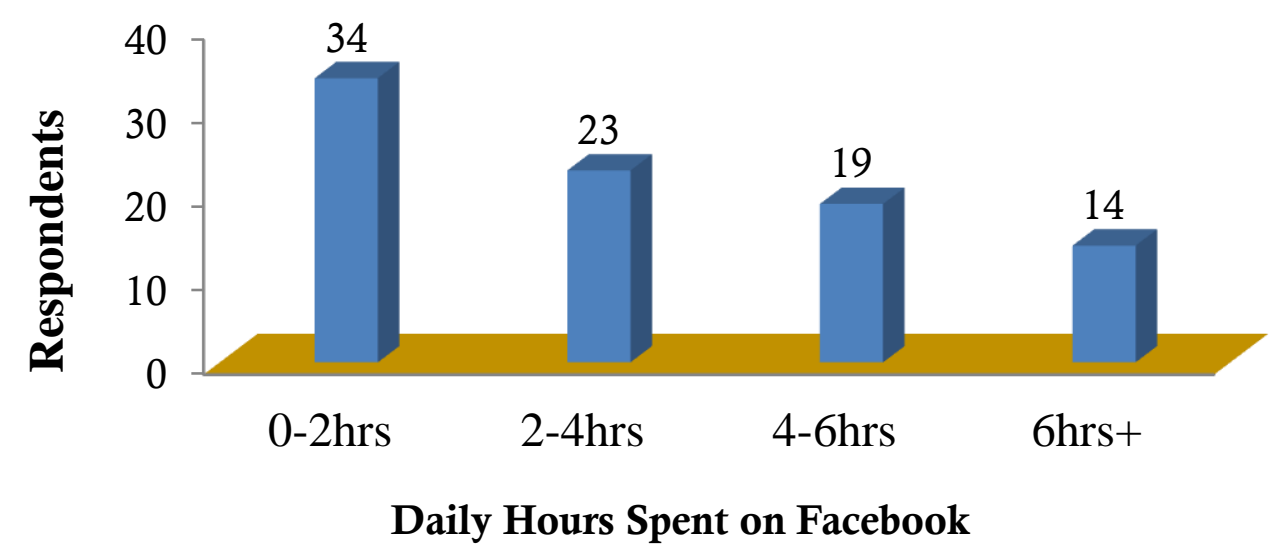

Source: Fieldwork, 2018

Figure 2. Time Spent on Facebook Daily

Figure 2 suggests that majority of the sample (37.8\%) spend between 0-2 hours on Facebook daily. Meanwhile, 25.6\% spend between 2-4 hours a day on Facebook, 21.1\% spend between 4-6 hours a day on Facebook, and 15.6\% spend 6 hours and above on Facebook daily.

Then, 67 respondents (74.4\%) agree that they belong to Facebook forums as opposed to 23 (25.6\%) who do not belong to any forum. Of those who belong to Facebook forums, majority (60\%) belong to between 1-5 WhatsApp forums, $8.9 \%$ belong to between 6-10 forums, $4.4 \%$ are between 11-15 groups, and 1.1\% belongs to between 16-20 Facebook forums.

Respondents acknowledged the issues they mostly discuss on Facebook as presented in the following figure:

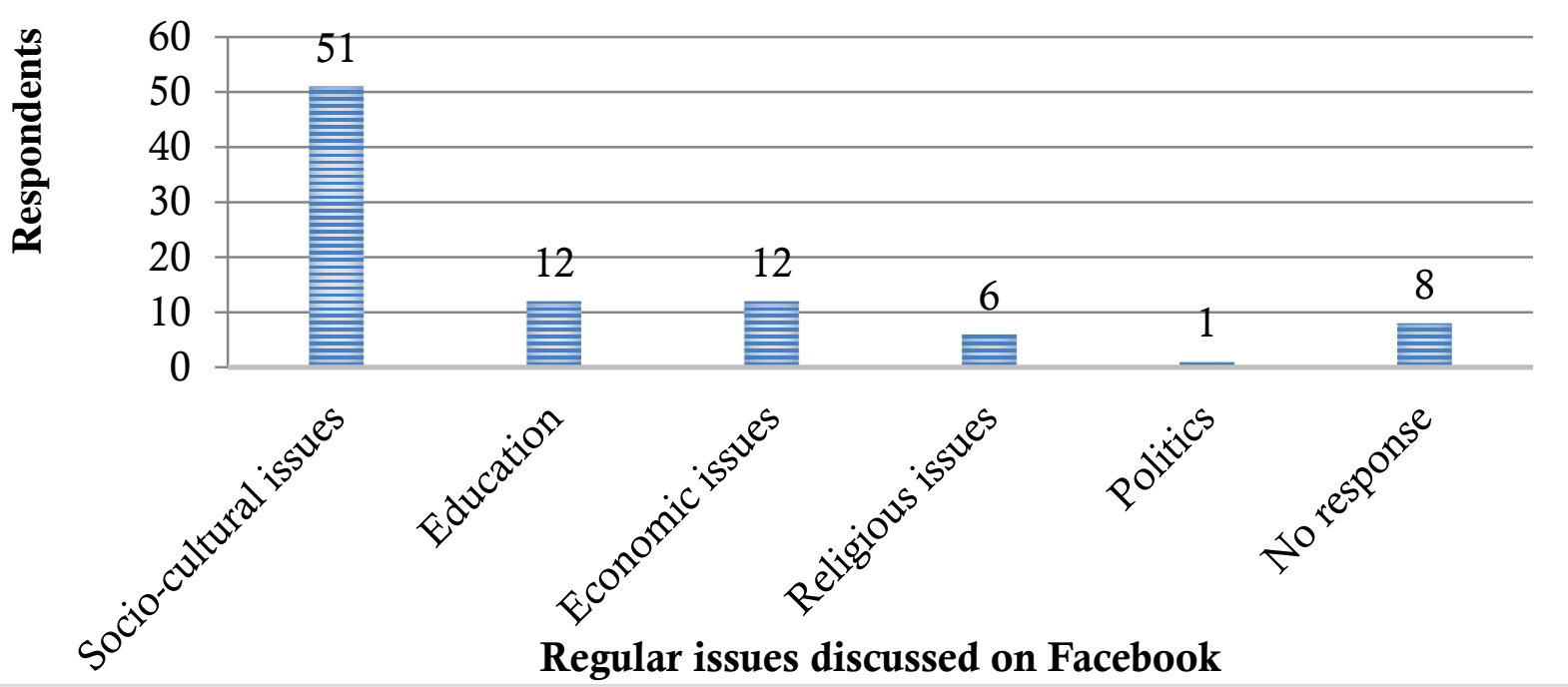

Source: Fieldwork, 2018

Figure 3. Most regular issues discussed on Facebook

From Figure 3, socio-cultural issues top the chart of priority issues respondents discuss on Facebook (51 respondents). Meanwhile, politics is the least issue discussed $(p=0.792)$. Also, education and economic issues had 12 respondents respectively.

Furthermore, the frequency of these various issues is presented in Table 5. 
Table 5. Frequency of discussion on diverse issues on Facebook

\begin{tabular}{lcccccc}
\hline \multirow{2}{*}{ Issues } & \multicolumn{7}{c}{ Extent } \\
\cline { 2 - 7 } Community security & Always & Often & Sometimes & Rarely & Never & Total \\
& 7 & 5 & 9 & $\mathbf{1 2}$ & $\mathbf{5 7}$ & 90 \\
Education & $(7.8 \%)$ & $(5.6 \%)$ & $(10 \%)$ & $(\mathbf{1 3 . 3 \%})$ & $(\mathbf{6 3 . 3 \% )}$ & $(100 \%)$ \\
& 29 & 14 & 20 & 13 & 14 & 90 \\
Socio-cultural issues & $(32.2 \%)$ & $(15.6 \%)$ & $(22.2 \%)$ & $(14.4 \%)$ & $(15.6 \%)$ & $(90 \%)$ \\
& $\mathbf{3 8}$ & $\mathbf{2 3}$ & 13 & 7 & 9 & 90 \\
Politics & $(\mathbf{4 2 . 4 \% )}$ & $(\mathbf{2 5 . 6 \% )}$ & $(14.4 \%)$ & $(7.8 \%)$ & $(10 \%)$ & $(100 \%)$ \\
& 11 & 5 & 9 & 21 & 44 & 90 \\
Economic issues & $(12.2 \%)$ & $(5.6 \%)$ & $(10 \%)$ & $(23.3 \%)$ & $(48.9 \%)$ & $(100 \%)$ \\
& 16 & 11 & 23 & 20 & 20 & 90 \\
& $(17.8 \%)$ & $(12.2 \%)$ & $(25.6 \%)$ & $(22.2 \%)$ & $(22.2 \%)$ & $(100 \%)$ \\
Religious issues & 21 & 15 & 18 & 11 & 25 & 90 \\
\hline Souryyyyy & $(23.3 \%)$ & $(16.7 \%)$ & $(20 \%)$ & $(12.2 \%)$ & $(27.8 \%)$ & $(100 \%)$ \\
\hline
\end{tabular}

Source: Fieldwork, 2018

It can be deduced from Table 5 that, community security is the least discussed issue on Facebook between and amongst respondents (76.6\% are against discussing it). They tend to place much emphasis rather on socio-cultural issues. Politics also features with less emphasis, while education appears on the table with some degree of prominence as a subject of discussion.

Respondents have also identified the main challenges they face in using Facebook as follows: connectivity issues (35.6\%), flow of nonsensical messages (8.9\%), deceit (3.3\%), financial constraints (3.3\%), immorality (2.2\%), security $(1.1 \%)$, threats $(1.1 \%)$, conflict in opinion $(1.1 \%)$, and time consuming $(1.1 \%)$. Again, the security aspect features with low prominence, probably indicating that the adolescents are not yet exposed to security challenges involved with typical use of social media platforms like Facebook.

\section{WhatsApp Use}

Like Facebook, the use of WhatsApp was equally investigated amongst the sampled adolescents. A major point of convergence is in the degree of use of Facebook and WhatsApp. Respondents attested that these two social media platforms are of equal importance to them, and use them always at the same time. Once data is on, respondents noted mainly that they switch between Facebook and WhatsApp, mostly through their mobile phones.

Like Facebook, majority of respondents $(20,22.2 \%)$ indicated that they started using WhatsApp in 2015. Meanwhile, 2014, 2017, and 2018 each has 12 respondents (13.3\%) showing their start of use of WhatsApp. Only 16 respondents (17.8\%) used WhatsApp between 2009 and 2013, while 7 respondents (7.8\%) did not indicate the year they started using WhatsApp.

In addition, respondents categorized the different channels they use to access WhatsApp as follows:

Table 6. Devices used by respondents to access WhatsApp

\begin{tabular}{lcccccc}
\hline & \multicolumn{7}{c}{ Extent } \\
\cline { 2 - 6 } Device & Always & Often & Sometimes & Rarely & Never & Total \\
Mobile Phone & $\mathbf{4 9}$ & $\mathbf{1 5}$ & 14 & 11 & 1 & 90 \\
& $\mathbf{5 4 . 4 \% )}$ & $\mathbf{( 1 6 . 9 \% )}$ & $(15.5 \%)$ & $(12.2 \%)$ & $(1.1 \%)$ & $(100 \%)$ \\
Cyber Café & 7 & 1 & 10 & 19 & 33 & 90 \\
& $(7.8 \%)$ & $(1.1 \%)$ & $(11.1 \%)$ & $(21.1 \%)$ & $(58.9 \%)$ & $(90 \%)$ \\
Laptop & 13 & 9 & 8 & 16 & 44 & 90 \\
& $(14.4 \%)$ & $(10 \%)$ & $(8.9 \%)$ & $(17.8 \%)$ & $(48.9 \%)$ & $(100 \%)$ \\
\hline
\end{tabular}

Source: Fieldwork, 2018 
Table 6 shows that most respondents access WhatsApp on their mobile phones $($ mean $=4.1)$, while cyber cafés $($ mean $=$ $1.7)$ and access using the laptop (mean $=2.2)$ have relatively low ratings.

Again, respondents rated the time of the day they prefer accessing WhatsApp as seen in Table 7 below:

Table 7. Time of the day respondents prefer accessing WhatsApp

\begin{tabular}{lcc}
\hline Period & Frequency & Percent \\
\hline Evening & 41 & 45.6 \\
Afternoon & 19 & 21.1 \\
Morning & 16 & 17.8 \\
Late into the night & 14 & 15.6 \\
Total & $\mathbf{9 0}$ & $\mathbf{1 0 0}$ \\
\hline
\end{tabular}

Source: Fieldwork, 2018

As shown in Table 7, majority of respondents prefer accessing WhatsApp in the evening (45.6\%). This is followed by access in the afternoon (21\%), morning, and late into the night (15\%). It can thus be summed that majority of respondents interactions with WhatsApp content takes place in the evening.

Respondents were also asked to indicate the frequency with which they communicate with different persons on WhatsApp. This is shown in the Table 8.

Table 8. Respondents' communication with diverse persons on WhatsApp

\begin{tabular}{|c|c|c|c|c|c|c|}
\hline \multirow[b]{2}{*}{ Persons } & \multicolumn{6}{|c|}{ Extent } \\
\hline & Always & Often & Sometimes & Rarely & Never & Total \\
\hline \multirow[t]{2}{*}{ Male friends } & 41 & 10 & 24 & 13 & 2 & 90 \\
\hline & $(46.6 \%)$ & $(11.1 \%)$ & $(26.7 \%)$ & $(14.4 \%)$ & $(2.2 \%)$ & $(100 \%)$ \\
\hline \multirow[t]{2}{*}{ Female friends } & 46 & 13 & 17 & 13 & 1 & 90 \\
\hline & $(51.1 \%)$ & $(14.4 \%)$ & $(18.9 \%)$ & $(14.4 \%)$ & $(1.1 \%)$ & $(90 \%)$ \\
\hline \multirow[t]{2}{*}{ My parents } & 14 & 7 & 11 & 23 & 35 & 90 \\
\hline & $(15.6 \%)$ & $(7.8 \%)$ & $(12.2 \%)$ & $(25.6 \%)$ & $(38.9 \%)$ & $(100 \%)$ \\
\hline \multirow[t]{2}{*}{ Relatives } & 19 & 8 & 19 & 29 & 15 & 90 \\
\hline & $(21.1 \%)$ & $(8.9 \%)$ & $(21.1 \%)$ & $(32.2 \%)$ & $(16.7 \%)$ & $(100 \%)$ \\
\hline
\end{tabular}

Source: Fieldwork, 2018

From Table 8 above, it can be seen that respondents communicate most with their female friends on WhatsApp $($ mean $=$ $4.0)$, followed by communication with male friends $($ mean $=3.8)$, relatives $($ mean $=2.8)$, and parents $($ mean $=2.3)-$ below average. Respondents have thus ranked their parents lowest in terms of WhatsApp exchange.

In addition, there is evidence that majority of the sample (37.8\%) spend between 0-2 hours on WhatsApp daily. Meanwhile, 25.6\% spend between 2-4 hours a day on WhatsApp, 21.1\% spend between 4-6 hours a day on WhatsApp, and $15.6 \%$ spend 6 hours and above on WhatsApp daily.

Meanwhile, 67 respondents (74.4\%) agree that they belong to WhatsApp groups as opposed to 23 (25.6\%) who do not belong to any group. Of those who belong to WhatsApp groups, majority (60\%) belong to between 1-5 WhatsApp groups, $8.9 \%$ belong to between 6-10 groups, $4.4 \%$ are between $11-15$ groups, and $1.1 \%$ belongs to between $16-20$ WhatsApp groups.

Respondents acknowledged the issues they mostly discuss on WhatsApp as presented in the following table: 
Table 9. Frequency of discussion of diverse issues on WhatsApp

\begin{tabular}{lcccccc}
\hline \multirow{2}{*}{ Issues } & \multicolumn{7}{c}{ Extent } \\
\cline { 2 - 7 } Community security & Always & Often & Sometimes & Rarely & Never & Total \\
& 7 & 5 & 9 & $\mathbf{1 2}$ & $\mathbf{5 7}$ & 90 \\
Education & $(7.8 \%)$ & $(5.6 \%)$ & $(10 \%)$ & $(\mathbf{1 3 . 3 \%})$ & $(\mathbf{6 3 . 3 \% )}$ & $(100 \%)$ \\
& 29 & 14 & 20 & 13 & 14 & 90 \\
Socio-cultural issues & $(32.2 \%)$ & $(15.6 \%)$ & $(22.2 \%)$ & $(14.4 \%)$ & $(15.6 \%)$ & $(90 \%)$ \\
& $\mathbf{3 8}$ & $\mathbf{2 3}$ & 13 & 7 & 9 & 90 \\
Politics & $(\mathbf{4 2 . 4 \% )}$ & $(\mathbf{2 5 . 6 \% )}$ & $(14.4 \%)$ & $(7.8 \%)$ & $(10 \%)$ & $(100 \%)$ \\
& 11 & 5 & 9 & 21 & 44 & 90 \\
Economic issues & $(12.2 \%)$ & $(5.6 \%)$ & $(10 \%)$ & $(23.3 \%)$ & $(48.9 \%)$ & $(100 \%)$ \\
& 16 & 11 & 23 & 20 & 20 & 90 \\
& $(17.8 \%)$ & $(12.2 \%)$ & $(25.6 \%)$ & $(22.2 \%)$ & $(22.2 \%)$ & $(100 \%)$ \\
Religious issues & 21 & 15 & 18 & 11 & 25 & 90 \\
\hline Souryyyyy & $(23.3 \%)$ & $(16.7 \%)$ & $(20 \%)$ & $(12.2 \%)$ & $(27.8 \%)$ & $(100 \%)$ \\
\hline
\end{tabular}

Source: Fieldwork, 2018

Just like Facebook, community security is given less attention on respondents' WhatsApp discussions. Rather, socio-cultural issues take centre stage.

The challenges respondents face in using WhatsApp are similar to those of Facebook; - with connectivity issues ranked highest and security concerns ranked amongst the lowest.

\section{Social Media (Facebook and WhatsApp) use during the Cameroon Anglophone Crisis}

The type of messages users come across on social media concerning a crisis are likely to shape their opinions, beliefs, attitudes, and behaviours about the crisis. This explains why respondents in this survey were asked to indicate the degree to which they interact with certain types of content on social media. The responses are tabulated in Table 10 below:

Table 10. Respondents' interaction with messages on the Cameroon Anglophone Crisis

\begin{tabular}{|c|c|c|c|c|c|c|}
\hline \multirow[b]{2}{*}{ Messages } & \multicolumn{6}{|c|}{ Extent } \\
\hline & Always & Often & Sometimes & Rarely & Never & Total \\
\hline Hate & 25 & 3 & 7 & 11 & 44 & 90 \\
\hline & $(27.8 \%)$ & $(3.3 \%)$ & $(7.8 \%)$ & $(12.2 \%)$ & $(48.9 \%)$ & $(100 \%)$ \\
\hline Use of violence as solution to the crisis & $\begin{array}{c}21 \\
(23.3 \%)\end{array}$ & $\begin{array}{c}6 \\
(6.7 \%)\end{array}$ & $\begin{array}{c}11 \\
(12.2 \%)\end{array}$ & $\begin{array}{c}13 \\
(14.4 \%)\end{array}$ & $\begin{array}{c}39 \\
(43.3 \%)\end{array}$ & $\begin{array}{c}90 \\
(90 \%)\end{array}$ \\
\hline Credibility of the Anglophone course & $\begin{array}{c}22 \\
(24.4 \%)\end{array}$ & $\begin{array}{c}10 \\
(11.1 \%)\end{array}$ & $\begin{array}{c}9 \\
(10 \%)\end{array}$ & $\begin{array}{c}8 \\
(8.9 \%)\end{array}$ & $\begin{array}{c}41 \\
(45.6 \%)\end{array}$ & $\begin{array}{c}90 \\
(100 \%)\end{array}$ \\
\hline School boycott & $\begin{array}{c}28 \\
(31.1 \%)\end{array}$ & $\begin{array}{c}8 \\
(8.9 \%)\end{array}$ & $\begin{array}{c}16 \\
(17.8 \%)\end{array}$ & $\begin{array}{c}12 \\
(13.3 \%)\end{array}$ & $\begin{array}{c}26 \\
(28.9 \%)\end{array}$ & $\begin{array}{c}90 \\
(100 \%) \\
\end{array}$ \\
\hline
\end{tabular}

Source: Fieldwork, 2018

Majority of respondents attest that they do not regularly interact with content relating to hate (48.9\%), use of violence as means to end the crisis (39\%), credibility of the Anglophone course (45\%), and school boycott (28.9\%). Their low exposure to these contents is thus likely to enable them maintain a positive attitude towards the crisis. In addition, considering that these adolescence are of the younger population, it can be deciphered from this data that the ill effects if the crisis, as manifested by some social media enthusiasts, have not infiltrated the minds of the adolescents. Hence, it is necessary to take precautionary measures to enable the adolescence stay off such harmful content on social media platforms like Facebook and WhatsApp.

Respondents also rated the extent to which they willingly watch certain videos relating to the Anglophone Crisis. The responses are scaled below: 
Table 11. Respondents' viewership of videos relating to the Cameroon Anglophone Crisis

\begin{tabular}{lcccccc}
\hline \multirow{2}{*}{ Video Type } & \multicolumn{7}{c}{ Extent } \\
\cline { 2 - 7 } How to use a gun & Always & Often & Sometimes & Rarely & Never & Total \\
& 6 & 2 & 3 & 5 & $\mathbf{7 4}$ & 90 \\
How to make bombs & $(6.7 \%)$ & $(2.2 \%)$ & $(3.3 \%)$ & $(5.6 \%)$ & $\mathbf{( 8 2 . 2 \% )}$ & $(100 \%)$ \\
& 1 & 1 & 0 & 5 & $\mathbf{8 3}$ & 90 \\
Freedom fighters & $(1.1 \%)$ & $(1.1 \%)$ & $(0 \%)$ & $(5.6 \%)$ & $\mathbf{( 9 2 . 2 \% )}$ & $(90 \%)$ \\
& 26 & 6 & 11 & 14 & $\mathbf{3 3}$ & 90 \\
Hate & $(28.9 \%)$ & $(6.7 \%)$ & $(12.2 \%)$ & $(15.6 \%)$ & $\mathbf{( 3 6 . 7 \% )}$ & $(100 \%)$ \\
& 25 & 5 & 11 & 15 & $\mathbf{3 4}$ & 90 \\
Activists & $(27.8 \%)$ & $(5.6 \%)$ & $(12.2 \%)$ & $(16.7 \%)$ & $\mathbf{( 3 7 . 8 \% )}$ & $(100 \%)$ \\
directing the course & 18 & 9 & 7 & 8 & $\mathbf{4 8}$ & 90 \\
\hline
\end{tabular}

Source: Fieldwork, 2018

Evidence in Table 11 indicates that in most cases, respondents "never" expose themselves to negative vices portrayed by social media (Facebook and WhatsApp). Only a minimal of the sample indicate that they expose themselves to these violent contents on social media. The use of guns and the making of bombs are such violent practices that are capable of radicalizing the young ones. The fact that they do not expose themselves to such content is proof that they are less likely to be negatively affected by the crisis.

To strengthen this argument, respondents were asked to rate their attitude towards the crisis based on the content, especially video, that they view on social media relating to the crisis. This is shown in table 12 below:

Table 12. Respondents' attitude towards the Cameroon Anglophone Crisis

\begin{tabular}{lcccccc}
\hline & \multicolumn{5}{c}{ Agreement / Disagreement } \\
\cline { 2 - 7 } \multicolumn{1}{c}{ Video Type } & $\begin{array}{c}\text { Strongly } \\
\text { agree }\end{array}$ & Agree & Neutral & Disagree & $\begin{array}{c}\text { Strongly } \\
\text { disagree }\end{array}$ & Total \\
Desire to join the course & 19 & 6 & 10 & 7 & $\mathbf{4 8}$ & 90 \\
& $(21.1 \%)$ & $(6.7 \%)$ & $(11.1 \%)$ & $(7.8 \%)$ & $\mathbf{( 5 3 . 3 \% )}$ & $(100 \%)$ \\
Desire to become violent & 12 & 6 & 6 & 8 & $\mathbf{5 8}$ & 90 \\
& $(13.3 \%)$ & $(6.7 \%)$ & $(6.7 \%)$ & $(8.9 \%)$ & $(\mathbf{6 4 . 4 \% )}$ & $(90 \%)$ \\
$\begin{array}{l}\text { Desire to foster the course } \\
\text { informant }\end{array}$ & 12 & 6 & 9 & 9 & $\mathbf{5 4}$ & 90 \\
$\begin{array}{l}\text { Desire to contribute towards a } \\
\text { solution to the crisis }\end{array}$ & $(13.3 \%)$ & $(6.7 \%)$ & $(10 \%)$ & $(10 \%)$ & $\mathbf{( 6 0 \% )}$ & $(100 \%)$ \\
\hline
\end{tabular}

Source: Fieldwork, 2018

From all indications, the adolescents sampled in this research have a more positive attitude towards the Cameroon Anglophone Crisis, than negative attitudes. This is exemplified as up to $73.4 \%$ of the respondents agree that they are willing to contribute towards a solution to end the current socio-political crisis rocking the Northwest and Southwest regions of Cameroon. This further explains and strengthens their attitudes towards social media content, with less emphasis and exposure to content that is geared towards reinforcing the crisis.

In addition, majority of the respondents disagree with any intentions to be active members of the Anglophone course / crisis $(61.1 \%)$. They are also against any form of violence, and as such, have no desires and intentions of becoming violent $(73.3 \%)$. Equally, the respondents are in no way willing to foster the ongoing crisis by serving as informants (70\%). 
Research question 2: What are the various dimensions of security threats that result from the use of Social Media platforms by adolescents in Buea, Cameroon?

\section{Dimensions of Security Threats}

The following ratings pertain to respondents' opinions on different dimensions of security threats.

Table 13. Dimensions of security threats

\begin{tabular}{|c|c|c|c|c|c|c|}
\hline Statement & $\begin{array}{l}\text { Strongly } \\
\text { agree } \\
(\mathbf{1 0 0 \%})\end{array}$ & $\begin{array}{l}\text { Agree } \\
(\mathbf{7 5 \%})\end{array}$ & $\begin{array}{c}\text { Neutral } \\
(50 \%)\end{array}$ & $\begin{array}{c}\text { Disagree } \\
(25 \%)\end{array}$ & $\begin{array}{l}\text { Strongly } \\
\text { disagree } \\
(0 \%)\end{array}$ & Total \\
\hline Like any other technology, Facebook\& & 56 & 18 & 11 & 2 & 3 & 90 \\
\hline WhatsApp have positive and negative effects & $(62.2 \%)$ & $(20 \%)$ & $(12.2 \%)$ & $(2.2 \%)$ & $(3.3 \%)$ & $(100 \%)$ \\
\hline $\begin{array}{l}\text { Facebook\& WhatsApp influence the language of } \\
\text { adolescents (Hate/violent speeches) }\end{array}$ & $\begin{array}{c}34 \\
(37.8 \%)\end{array}$ & $\begin{array}{c}24 \\
(26.7 \%)\end{array}$ & $\begin{array}{c}16 \\
(17.8 \%)\end{array}$ & $\begin{array}{c}6 \\
(6.7 \%)\end{array}$ & $\begin{array}{c}10 \\
(11.1 \%)\end{array}$ & $\begin{array}{c}90 \\
(100 \%)\end{array}$ \\
\hline $\begin{array}{l}\text { In the course of Facebook \& WhatsApp use, one } \\
\text { frequently comes across obscene/violent } \\
\text { images }\end{array}$ & $\begin{array}{c}40 \\
(44.4 \%)\end{array}$ & $\begin{array}{c}21 \\
(23.3 \%)\end{array}$ & $\begin{array}{c}12 \\
(13.3 \%)\end{array}$ & $\begin{array}{c}7 \\
(7.8 \%)\end{array}$ & $\begin{array}{c}10 \\
(11.1 \%)\end{array}$ & $\begin{array}{c}90 \\
(100 \%)\end{array}$ \\
\hline $\begin{array}{l}\text { Facebook \& WhatsApp influence the dressing } \\
\text { pattern of adolescents }\end{array}$ & $\begin{array}{c}31 \\
(34.4 \%)\end{array}$ & $\begin{array}{c}23 \\
(25.6 \%)\end{array}$ & $\begin{array}{c}13 \\
(14.4 \%)\end{array}$ & $\begin{array}{c}8 \\
(8.9 \%)\end{array}$ & $\begin{array}{c}15 \\
(16.7 \%)\end{array}$ & $\begin{array}{c}90 \\
(100 \%)\end{array}$ \\
\hline $\begin{array}{l}\text { Facebook \&WhatsApp limit face to face } \\
\text { communication of adolescents in the Buea } \\
\text { community }\end{array}$ & $\begin{array}{c}36 \\
(40 \%)\end{array}$ & $\begin{array}{c}13 \\
(14.4 \%)\end{array}$ & $\begin{array}{c}13 \\
(14.4 \%)\end{array}$ & $\begin{array}{c}15 \\
(16.7 \%)\end{array}$ & $\begin{array}{c}13 \\
(14.4 \%)\end{array}$ & $\begin{array}{c}90 \\
(100 \%)\end{array}$ \\
\hline $\begin{array}{l}\text { Facebook \& WhatsApp influence decision } \\
\text { making in pertinent issues (like the brand of } \\
\text { goods to buy) }\end{array}$ & $\begin{array}{c}30 \\
(33.3 \%)\end{array}$ & $\begin{array}{c}21 \\
(23.3 \%)\end{array}$ & $\begin{array}{c}10 \\
(11.1 \%)\end{array}$ & $\begin{array}{c}12 \\
(13.3 \%)\end{array}$ & $\begin{array}{c}17 \\
(18.9 \%)\end{array}$ & $\begin{array}{c}90 \\
(100 \%)\end{array}$ \\
\hline
\end{tabular}

Source: Fieldwork, 2018

There is evidence that adolescents are aware of the negative and positive effects of social media (82.2\%). Notwithstanding, the use of these media, as seen in this research, is skewed towards positive than negative ends. Thus, the same social media can be used as a positive force to positively influence the minds of adolescents towards positive content aimed at instituting peace to end the crisis. The young too have their role to play. A major trend that this study reveals is the third person effect - the believe by respondents that Facebook and WhatsApp have the potential to influence the language of other adolescents (64.5\%), though this influence is seen less on respondents of this survey.

Research question 3: What possible measures can be put in place to counter the ill effects of social networking on adolescents?

\section{Measures to counter ill effects of Facebook and WhatsApp on Adolescents in Buea Municipality}

Respondents agreed / disagreed to the following options regarding measures to counter the ill effects of Facebook and WhatsApp as follows:

Table 14. Measures to counter ill effects of Facebook and WhatsApp on Adolescents in Buea Municipality

\begin{tabular}{|c|c|c|c|c|c|c|}
\hline Effects & $\begin{array}{l}\text { Strongly } \\
\text { agree } \\
(100 \%)\end{array}$ & $\begin{array}{l}\text { Agree } \\
(75 \%)\end{array}$ & $\begin{array}{c}\text { Neutral } \\
(50 \%)\end{array}$ & $\begin{array}{l}\text { Disagree } \\
(25 \%)\end{array}$ & $\begin{array}{l}\text { Strongly } \\
\text { disagree } \\
(0 \%)\end{array}$ & Total \\
\hline $\begin{array}{l}\text { Poor behaviours resulting from the wrong use } \\
\text { of Facebook \& WhatsApp have far reaching } \\
\text { consequences if not curbed }\end{array}$ & $\begin{array}{c}51 \\
(56.7 \%)\end{array}$ & $\begin{array}{c}20 \\
(22.2 \%)\end{array}$ & $\begin{array}{c}7 \\
(7.8 \%)\end{array}$ & $\begin{array}{c}3 \\
(3.3 \%)\end{array}$ & $\begin{array}{c}9 \\
(10 \%)\end{array}$ & $\begin{array}{c}90 \\
(100 \%)\end{array}$ \\
\hline $\begin{array}{l}\text { Parents should control Facebook \& WhatsApp } \\
\text { use for their children }\end{array}$ & $\begin{array}{c}46 \\
(51.1 \%)\end{array}$ & $\begin{array}{c}17 \\
(18.9 \%)\end{array}$ & $\begin{array}{c}5 \\
(5.6 \%)\end{array}$ & $\begin{array}{c}7 \\
(7.8 \%)\end{array}$ & $\begin{array}{c}15 \\
(16.7 \%)\end{array}$ & $\begin{array}{c}90 \\
(100 \%)\end{array}$ \\
\hline $\begin{array}{l}\text { Educative programs should be included in } \\
\text { school curricula, public and private media on } \\
\text { the proper use of Facebook and WhatsApp }\end{array}$ & $\begin{array}{c}64 \\
(70 \%)\end{array}$ & $\begin{array}{c}13 \\
(14.4 \%)\end{array}$ & $\begin{array}{c}5 \\
(5.6 \%)\end{array}$ & $(1.1 \%)$ & $\begin{array}{c}7 \\
(7.8 \%)\end{array}$ & $\begin{array}{c}90 \\
(100 \%)\end{array}$ \\
\hline
\end{tabular}

Source: Fieldwork, 2018

Overall, 78.9\% of respondents agree that social media (Facebook and WhatsApp) excesses have to be curbed to prevent the widespread of such negative influences. In addition, $70 \%$ of respondents hold the view that parental control regarding the use of Facebook and WhatsApp by adolescents is paramount. Respondents also agree overwhelmingly $(84.4 \%)$ to the inclusion of educative programs in school curricula and respective public and private media on the proper use of Facebook and WhatsApp. 


\section{Discussion, Conclusion, and Recommendations}

The literature examined in this study is limited to the use of social media (Facebook and WhatsApp) by adolescents. This is done in normal daily life, as well as during crisis situations. The study is further confined geographically to four areas noted for security concerns in Buea, Cameroon (Muea, Mile 16, Molyko, and Bomaka). It is therefore hoped that, the results obtained in this research will be used to establish external validity (generalisability) within the larger context of studying adolescent use of social media, and the likely effects that content they come across and interact with have on their lives. Boyd and Ellison (2008) had earlier observed that social media play a great role in the daily lives of adolescents.

Facebook and WhatsApp were regarded in this research as interactive technological tools wherein communities share, create, co-create, discuss, and modify user-generated content. This is the same observation that Kaplan and Haenlein (2010) made concerning the actual use of social media platforms. Based on findings of this research, adolescents in Buea interact with different content on Facebook and WhatsApp. However, it was discovered that they are more prone to positive than negative content.

When asked to indicate their exposure to content regarding the Cameroon Anglophone Crisis for instance, they indicated they see such content. Notwithstanding, when a specific issue like the spread of hate messages was studied, up to $61.1 \%$ of respondents indicated that they do not discuss and share such content on social media, as opposed to $31.1 \%$ who indicated they discuss and share hate messages on social media.

In addition, the research reveals that security is the least discussed issue on Facebook and WhatsApp between and amongst respondents (76.6\% are against discussing it). They tend to place much emphasis rather on socio-cultural issues. Politics also features with less emphasis, while education appears on the table with some degree of prominence as a subject of discussion. This confirms the assertion by Madden et al. (2013) and Garcia-Gomez $(2017,2018)$ that, social media discussions are mostly initiated and followed up by those who share similar interest. Thus, the adolescents have the same mind-sets as those they share contents with on social media. They get to feel like they are part of a group of like-minded friends, and can visualize their network of relationship.

Just as the United Nations observed, community security means protecting people from the loss of traditional relationships and values and from sectarian and ethnic violence. In the same vein, adolescents are conceived as a vulnerable group that needs to be protected in Cameroon. The traditional values of peace have to be maintained and transmitted to the younger generation.

This explains why, it is good news that majority of adolescents sampled in this study have little or no relationship with videos relating to how bombs are produced, videos relating to how to use a gun, and how to adopt violent behaviour from social media. The adolescents sampled in this research have a more positive attitude towards the Cameroon Anglophone Crisis, than negative attitudes. This is exemplified as up to $73.4 \%$ of the respondents agree that they are willing to contribute towards a solution to end the current socio-political crisis rocking the Northwest and Southwest regions of Cameroon. This further explains and strengthens their attitudes towards social media content, with less emphasis and exposure to content that is geared towards reinforcing the crisis. The findings are therefore within the range of the UN's recommendations on strategies needed to keep a community at peace, especially in cases where young children are involved.

It may become problematic if one places children within the context of this broader definition. An immediate psychological reaction will be that these children will put social media to wrong use, since they are left alone. At this point, the social media world is exposed to them, and they can send across any content, as well as consume any content. This is likely to expose the children to different dimensions of security threats. However, the findings of this study confirm that majority of adolescents are moderate and responsible consumers of social media content. Attention can thus be paid more on assisting these children discover more positive uses they can make of social media. This will enhance their educational and socio-cultural lives - the type of contents they mostly associate with, as this study shows.

Technological determinism, one of the theoretical frameworks used in this research, also has great implications on results of this study. Based on the theory's assumption, media technology shapes how we as individuals in a society think, feel, act, and how the society operates as we move from one technological age to another. This is true, considering that social media has become a way of life.

In some circles, Facebook and WhatsApp are inevitable. Fortunately, the adolescents surveyed in this research have the same feeling about the social media world. Hence, the technologies, in some way, help to shape how these children live, think, and interact with others in society. Findings of this research also confirm that most of these social media connections are made through the mobile phone. This therefore puts the mobile phone at the heart of technological innovations in the $21^{\text {st }}$ Century, capable of transforming lives and mind-sets in every sector. Children are part of the technological revolution, thereby justifying why their attitudes and behaviours should be studied in the face of social media revolution. 
Regarding the Social Learning Theory, Bandura notes that learning occurs through observations and interactions with other people. Essentially, people learn by watching others and then imitating these actions. This theory is also instrumental in this research. Adolescents live in social environments where they interact with other persons in society.

It can thus be predicted that if the online attitudes and behaviours of those the adolescents interact with are negative and violent, the children can in turn copy such attitudes. This will therefore mean that society will automatically be plunged into chaos, thereby raising security concerns. This study confirms that adolescents learn from, and interact with others in the social media environment. However, this learning is more tilted towards the positive development of the adolescents, than on negative influences. If this social media influence was mostly found to be negative, this could then be conceived as a real problem. This is because the adolescents, after observing such aggressive behaviours, would tend to be aggressive afterwards.

This discussion also makes reference to Livingstone who mentions pornography as a security threat to adolescents. Per his conception, adolescents' use of social media cannot be discussed exhaustively without making reference to pornography and the use of gruesome pictures. Respondents of this study have confirmed that in the use of social media, one comes across these types of images and pictures (pornography) $-67.7 \%$. However, the respondents have distanced themselves from the active use of these types of images and pictures.

Madden et al. (2013) and Dobson (2015) report that teens' Facebook friends are a reflection of their offline social network of friends. From the findings of this research, the type of friends adolescents have are more positive than negative in social media use. It also goes to confirm that social media is a new way of life whereby friends online are likely to be the same friends offline. Peer influence is thus conceived here as an important variable that determines the aggressive or non-aggressive use of social media content by adolescents. This also has a relationship with the time spent on social media, as this study shows that majority of adolescents often use social media, with an average of 0-2hours of connectivity a day.

It can also be itemized that, from the results of this study, the subject of responsible democracy is important for discussion. Kassam (2013) notes that, social media is a powerful tool for the dissemination of citizenship and democratic values and principles. If taken seriously therefore, children should be put within the larger context of these values and principles, and avoid negative distractions that ensue from everyday use of the social media, notably Facebook and WhatsApp.

\section{Objective 1: To examine how adolescents in Buea, Cameroon, use Facebook and WhatsApp}

To answer this objective, respondents were asked to identify the frequency with which they use Facebook and WhatsApp, including preferred time of Facebook and WhatsApp use, and the persons they usually communicate with. Also, respondents were questioned on the year they started using Facebook and WhatsApp, with evidence suggesting that majority started using Facebook and WhatsApp in 2015.

Again, most respondents access Facebook and WhatsApp on their mobile phones (mean $=4.1$ ), while cyber cafés and access using the laptop have relatively low ratings. The above statistics conform the power of the mobile phone in the $21^{\text {st }}$ Century, especially as everyone, and even adolescents want to identify with the device through ownership and use. The most preferred time of these social media use is in the evening. Communication mostly flows with female friends, with the lowest ratings being communication with the adolescents and their parents (probably because some live with their parents).

Socio-cultural issues top the chart of priority issues respondents discuss on Facebook and WhatsApp, followed by education. Meanwhile, security and politics feature as the least discussed issues on these social media platforms.

Majority of respondents also attest that they do not regularly interact with content relating to hate, use of violence as means to end the current Anglophone crisis, credibility of the Anglophone course, and school boycott. Their low exposure to these contents is thus likely to enable them maintain a positive attitude towards the crisis. Such positive attitude is also likely to prevent the adolescents from engaging in violent behaviours that could pose as security threats.

\section{Objective 2: To examine the various dimensions of security threats resulting from the use of social media platforms by} adolescents in Buea, Cameroon

Evidence obtained in this research shows that adolescents are aware of the negative and positive effects of social media $(82.2 \%)$. Notwithstanding, the use of these media, as seen in this research, is skewed towards positive than negative ends. Thus, the same social media can be used as a positive force to positively influence the minds of adolescents towards positive content aimed at instituting peace to end the crisis. The young too have their role to play.

In addition, this study reveals a key trend - the third person effect. Adolescents believe that Facebook and WhatsApp have the potential to influence the language of other adolescents $(64.5 \%)$, though this influence is seen less on 
respondents of this survey.

\section{Objective 3: To assess possible ways by which the social media's influence on adolescents can be mitigated.}

Findings show that in all, 78.9\% of respondents agree that social media (Facebook and WhatsApp) excesses have to be curbed to prevent the widespread of such negative influences. In addition, $70 \%$ of respondents hold the view that parental control regarding the use of Facebook and WhatsApp by adolescents is paramount. Respondents also agree overwhelmingly (84.4\%) to the inclusion of educative programs in school curricula and respective public and private media on the proper use of Facebook and WhatsApp.

In summary therefore, the objectives of the research have been met. Adolescents in Buea use Facebook and WhatsApp on a routine basis. They are aware of the negative influences of these platforms especially during crisis situations. However, their attitude is more positive towards the use of these media. Majority do not engage with negative content on Facebook and WhatsApp.

The development that has happened in the field of ICT has not only changed a great deal in the field of communication, but it has also affected communities and societies around the world. The communities of Buea, capital of the South West Region of Cameroon are no exception. In today's interconnected world, social media can offer people channels to interact with numerous people at the same time as well as exchange ideas experiences. To some, they serve as platforms to for relaxation while for others it served as a platform for discussing social and cultural issues. While sharing photos and video chips of diverse contents ranging from dressing styles, hair styles, pornographic images and sometimes propagating hate messages. This study firstly, sought to find out the pattern young people use social on the answers of the interviewees, Social media can be accessed almost anytime and anywhere in Cameroon. Mobile phones were found to be the most popular devices to access social media and seemed to contribute to closing the digital divide in the country. It was found that, adolescents, in the Buea communities were actively discussing socio-cultural issues than they did for security and political issues. This contradict the general view on public opinion holds that, youths in Buea Sub division are active participants on social media in relation to security issues.

It was found that, although most respondents did not discuss political issues on social media, no reason was advanced to justify their claim. There is certainly the likelihood that, most respondents did not discuss political issues, following the precarious situation at hand (the Cameroon Anglophone crisis which has led to the death of over 3000 people and more than 200,000 displaced), due to the fear of being implicated.

\section{Recommendations}

The following recommendations are made in connection with the results obtained in this study:

All stakeholders, especially the ministry of communication in Cameroon and network providers, need to come up with means of filtering information that reaches the young people.

In the same light, the government should create policies to determine which website is used by which particular group of persons, and in the same light come up with policies to check out unfair reporting of media which have the likelihood of destabilising the society. Some websites and social networking sites should be completely prohibited, especially those that portray gruesome and violent images and immoral issues.

Also, the Ministries concerned should institute educative programs in school curricula, as well as public and private media on the proper use of Facebook and WhatsApp. Courses should be taught the children on effective use of social media platforms. The children should also be made to see into the necessity of paying attention to programmes on radio and television, regarding the proper use of these technologies. Adolescents can as well download research content online and use positively.

Parental control should be strengthened, especially with adolescents who are new comers to social media use. This means parents should also move with the times by adopting positive attitudes towards the use of Facebook and WhatsApp. The technologies should not be ignored, since they have come to stay. It is more beneficial therefore, if every parent masters how the technologies work, so that they can orientate their children in the use of the platforms. This can be achieved at home and through community seminars.

Adolescents should continuously be protected from negative influences of social media. This especially consists of educating them on the ills of social media, and encouraging them to adopt positive attitudes regarding social media use, as this research mostly shows. Even more interestingly, adolescents surveyed in this research do not use the social media negatively to learn and adopt negative and aggressive behaviours that pose as security threats. So, it will be important to find out in further research where those who perpetrate insecurity in these areas surveyed come from. Such research should also be able to investigate elements of pretence, and uncover whether respondents concealed information for fear of the unknown. 


\section{References}

Amin, M. E. (2005). Social science research: Conception, methodology and analysis. Kampala, Uganda: Makerere University Printery.

Bandura, A. (1977). Social learning theory. Englewood Cliffs, NJ: Prentice Hall.

Berger, A. A. (1995). Essentials of mass communication theory. London: Sage. https://doi.org/10.4135/9781483345420

Boyd D., \& Ellison, N. (2008). Social Network Sites: Definition, history and scholarship. Journal of Computer-Mediated Communication, 13, 210-230. https://doi.org/10.1111/j.1083-6101.2007.00393.x

Buhari, S. R., Ahmad, G. I., \& Ashara, B. H. (2014). Use of social media among students of Nigerian Polytechnic. International Conference on Communication, Media, Technology and Design, 24-26 April, Istanbul-Turkey.

Chadwish, A. (2006). Internet politics: States, citizens and new communication technologies. New York: Oxford University Press.

Common Sense Media. (2009). Is technology networking changing childhood? A national poll. San Francisco, CA: Common Sense Media.

Cronbach, L. J. (1951). Coefficient alpha and the internal structure of tests. Psychometrika, 16, $297-334$. https://doi.org/10.1007/BF02310555

Cunman, R. (2011). The role of Internet and social media in international relations. The Arab Revolution of 2011.

Dacey, J. S., \& Kenny, M. (1994). Adolescent development. Madison, WI: WCB Brown \& Benchmark Publishers.

Dobson, A. (2014a). Laddishness online: The possible significations and significance of 'performative shamelessness' for young women in the post-feminist context. Cultural Studies, 28(1), 142-164. https://doi.org/10.1080/09502386.2013.778893

Dobson, A. (2014b). Performative shamelessness on young women's social network sites: Shielding the self and resisting gender melancholia. Feminism \& Psychology, 24(1), 97-114. https://doi.org/10.1177/0959353513510651

Dobson, A. (2015). Postfeminist digital cultures: Femininity, social media, and self-representation. New York: Palgrave Macmillan. https://doi.org/10.1057/9781137404206

Drotner, K., \& Livingstone, S. (2008). Volume introduction. In K. Drotner and S. Livingstone (Eds.), The international handbook of children, media and culture. London: Sage.

Drussell, J. (2012). Social networking and interpersonal communication and conflict resolution skills among college freshmen.

García-Gómez, A. (2007). Habla conflictiva como acción social. Oviedo: Septem Ediciones.

García-Gómez, A. (2009). La conversacionalización del discurso mediático en la televisión británica. Ideología, poder y cambio social. Oviedo: Septem Ediciones.

García-Gómez, A. (2011). Regulating girlhood: Evaluative language, discourses of gender socialization and relational aggression. European Journal of Women's Studies, 18(3), 243-264. https://doi.org/10.1177/1350506811405817

García-Gómez, A. (2014). Deconstructing 'mean girls': Impolite verbal behaviours, on/offline self-representations and evaluative beliefs. In A. Sánchez Macarro and A.B Cabrejas Peñuelas (Eds.), New insights into gendered discursive practices: Language, gender and identity construction. Valencia: English in the World Series. Valencia: Universitat de Valencia, pp. 73-100.

García-Gómez, A. (2017). Teen girls and sexual agency: Exploring the intrapersonal and intergroup dimensions of sexting. Media, Culture and Society, 39(3), 391-407. https://doi.org/10.1177/0163443716683789

García-Gómez, A. (2018). From selfies to sexting: Tween girls, intimacy, and subjectivities. Girlhood Studies, 11(1), 43-58. https://doi.org/10.3167/ghs.2018.110105

Gohdes, A. R. (2015). Studying the Internet and violent conflict. Journal of Conflict Management and Peace Science, 35(1). https://doi.org/10.1177/0738894217733878

Hall, S. G. (1904). Adolescence: Its psychology and its relations to physiology, Anthropology and sociology, sex, crime, religion and education. Englewood Cliffs NJ: Prentice Hall. https://doi.org/10.1037/10618-000

Hayford, S. R., \& Furstenberg, F. F. (2008). Delayed adulthood, delayed desistance? Trends in the age distribution of problem behaviours. Arizona, USA. https://doi.org/10.1111/j.1532-7795.2008.00561.x 
Jolly, R., \& Ray, D. B. (2006). The human security framework and national human development reports: A review of experiences and current debates. New York: Human Development Report Office, UNDP.

Kaplan, A. M., \& Haenlein, M. (2010). Users of the world, unite! The challenges and opportunities of social media. Business horizons, 54, 241-251. https://doi.org/10.1016/j.bushor.2009.09.003

Kassam, A. (2013). Changing society using new technologies: Youth participation in the social media revolution and its implications for the development of democracy in Sub-Saharan Africa. Education and Information Technologies, 253-263. https://doi.org/10.1007/s10639-012-9229-5

Leavey, J. (2013). Social media and public policy: What is the evidence? Alliance for Useful Evidence, 1-40.

Lippmann, W. (1943). U.S. Foreign Policy: Shield of the Republic. Boston: Little, Brown and Company.

Livingstone, S. M., \& Bober, M. (2005). Children go online: Listening to young people's experiences. Department of Media and Communications, London School of Economics and Political Science.

Lowery, S., \& DeFleur, M. L. (1995). Milestone in mass communication research: Media effects. London: Longman Publishers.

Lustig, M. W., \& Koester, J. (1999). Intercultural competence. New York: Longman.

MacKenzie, D., \& Wajcman, J. (Eds.). (1999). The social shaping of technology. Buckingham: Open University Press.

Madden, M., Lenhart, A., Cortesi, S., Gasser, U., Duggan, M., Smith, A., \& Beaton, M. (2013). Teens, social media, and privacy. Pew Research Center.

Manoff, R. K. (1998). Role Plays; Potential media roles in conflict Prevention and management in Track Two. Rondenbosch South Africa: Centre for Conflict Resolution.

Mbayong, N. A. (2017). Assessing the impact in the growth of social media in Cameroon and user experience: The Case of Facebook. Journal of Accounting and Marketing, 6, 240. https://doi.org/10.4172/2168-9601.1000240

McLuhan, M. (1964). Understanding media: The extensions of man. New York: MIT Press.

Montagnese, A. (2011). Impact of social media on national security. Research paper-STEPI-AC-U-32011.2012313-0856.Doc.

Newson, A., Houghton, D., \& Patten, J. (2018). Exploiting the technology and protecting the enterprise, blogging and other social media. England: Gower Publishing Limited. https://doi.org/10.4324/9781315261485

Njoroge, R. (2013). Impacts of social media among the youth on behavior change: A case study of university students in selected universities in Nairobi. Nairobi, Kenya.

O'Reilly, T. (2005). What is Web 2.0 design patterns and business models for the next generation software? www.oreilly.com.

Pinzón, L. (2013). Beyond connectivity: The impacts of social media in urban development in Puerto Ayora. DPU Working Paper No 160.

Ringrose, J. (2006). A new universal mean girl: Examining the discursive construction and social regulation of a new feminine pathology. Feminism Psychology, 16(4), 405-424. https://doi.org/10.1177/0959353506068747

Ringrose, J. (2008). Just be friends: Exposing the limits of educational bully discourses for understanding teen girls' heterosexualized friendships and conflicts. British Journal of Sociology of Education, 29(5), 509-522. https://doi.org/10.1080/01425690802263668

Ringrose, J. (2010). Sluts, whore, fat slags and playboy bunnies: Teen girls' negotiations of 'sexy' on social networking sites and at school. In C. Jackson, C. Paechter and E. Renold (Eds.), Girls and education 3-16: Continuing concerns, new agendas. Basingstoke: Open University Press, pp. 170-182.

Ringrose, J., \& Eriksson, B. K. (2011). Gendered risks and opportunities? Exploring teen girls' digitized sexual identities in postfeminist media contexts. International Journal of Media and Cultural Politics, 7(2), 121-138. https://doi.org/10.1386/macp.7.2.121_1

Ringrose, J., \& Renold, E. (2012). Slut-shaming, girl power and 'sexualisation': Thinking through the politics of the international SlutWalks with teen girls. Gender and Education, 24(3), 333-343. https://doi.org/10.1080/09540253.2011.645023

Ringrose, J., Gill, R., Livingstone, S., \& Harvey, L. (2013). Teen girls, sexual double standards and 'sexting': Gendered value in digital image exchange. Feminist Theory, 14(3), 305-323. https://doi.org/10.1177/1464700113499853 
Safko, L., \& Brake, D. (2009). The Social Media Bible: Tactics, tools, and strategies for business success. Hoboken, NJ: John Wiley \& Sons.

The Hague Center for Strategic Studies (2011). Social networking: The security shakedown of shared information, No. 11.

UNDP Human Development Report. (1994). New Dimensions of Human Security, New York: UNDP.

Ungerer, C. (2012). Social media and national security, ASPI Strategic Policy Form, 1, 27 February.

United States National Security Strategy (2010). USA: Washington DC.

United States Youth Internet Safety Survey (2018). 2018 Biennial Child Protection Skill Building Conference. September 4.

Valkenburg, P.M., Peter, J., \& Walther, J.B. (2016). Media effects: Theory and research. Annual Review of Psychology, 67(1), 315-338. https://doi.org/10.1146/annurev-psych-122414-033608

Winner, L. (1977). Autonomous Technology. Cambridge, MA: MIT Press.

Zeitzoff, T. (2011). Using social media to measure conflict dynamics: An application to the 2008-2009 Gaza conflict. Journal of Conflict Resolution, 55(6), 938-969. https://doi.org/10.1177/0022002711408014

Zeitzoff, T. (2017). How social media is changing conflict. Journal of Conflict Resolution, 61(9), 1970-1991. https://doi.org/10.1177/0022002717721392

\section{Copyrights}

Copyright for this article is retained by the author(s), with first publication rights granted to the journal.

This is an open-access article distributed under the terms and conditions of the Creative Commons Attribution license which permits unrestricted use, distribution, and reproduction in any medium, provided the original work is properly cited. 